\title{
Comprehensive lung injury pathology induced by mTOR inhibitors
}

\author{
Guadalupe Aparicio ${ }^{1}$, Moisés B. Calvo ${ }^{2}$, Vanessa Medina ${ }^{1}$, Ovidio Fernández ${ }^{3}$, \\ Paula Jiménez ${ }^{4}$, Martina Lema ${ }^{5}$, Angélica Figueroa ${ }^{2}$, Luis M. Antón Aparicio ${ }^{3,6}$
}

1. Oncology Research, Lab INIBIC, A Coruña, Spain

2. INIBIC, A Coruña University Hospital, A Coruña, Spain

3. Medical Oncology Service, A Coruña University Hospital, A Coruña, Spain

4. Medical Oncology Service, Asturias Central Hospital, Oviedo, Spain

5. Pharmacy Service, A Coruña University Hospital, A Coruña, Spain

6. Medicine Department, University of A Coruña, A Coruña, Spain

\begin{abstract}
Interstitial lung disease is a rare side effect of temsirolimus treatment in renal cancer patients. Pulmonary fibrosis is characterised by the accumulation of extracellular matrix collagen, fibroblast proliferation and migration, and loss of alveolar gas exchange units. Previous studies of pulmonary fibrosis have mainly focused on the fibro-proliferative process in the lungs. However, the molecular mechanism by which sirolimus promotes lung fibrosis remains elusive. Here, we propose an overall cascade hypothesis of interstitial lung diseases that represents a common, partly underlying synergism among them as well as the lung pathogenesis side effects of mammalian target of rapamycin inhibitors.
\end{abstract}

Keywords

Interstitial lung disease; Pulmonary fibrosis; Sirolimus; ROS; Rapamycin 


\section{The mammalian target of rapamycin (mTOR)}

Rapamycin and its derivatives are immunosuppressor macrolides that block mammalian target of rapamycin (mTOR) functions and yield anti-proliferative activity in a variety of malignancies. Rapamycin analogues currently selected for clinical development are CCI-779 (Temsirolimus), RAD001 (Everolimus) and AP23573 (Fig. 1).

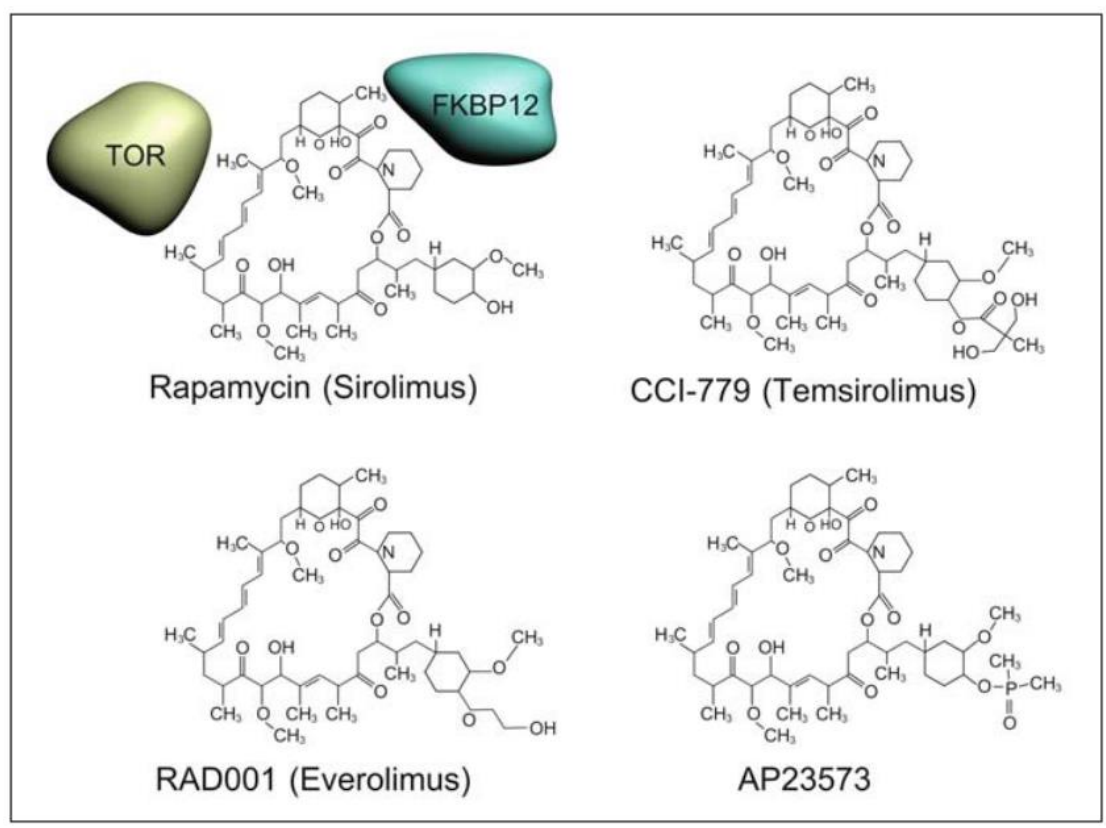

Fig. 1. Molecular structure of rapamycin and some of its analogs currently selected for clinical development. For the rapamycin, it is schematized the mode of binding to TOR (target of rapamycin) and FKBP12, its targets

mTOR was identified as the kinase target linked to the cellular protein FKBP12 (FK506binding protein). It was therefore also named FKBP-RAP associated protein (FRAP), RAP FKBP12 target (RAFT1) and RAP target (RAPT1). In the mammalian related proteins, mTOR are required for signalling translational initiation and therefore cell cycle progression from the G0/G1 to $\mathrm{S}$ phase. In humans, mTOR primarily appears to be a nutrient-sensing protein: $\mathrm{mTOR}$ is constitutively activated in the presence of growth factor and nutrients and acts as a master switch of cellular catabolism and anabolism.

The TOR proteins are members of the phosphoinositide 3-kinase-related kinase (PIKK) family, whose members (ATM, ATR, DNA-PK, hSMG1, mTOR and TRAPP in mammalian cells) transmit signals related to cell growth, proliferative and stress response [1]. Like the other PIKKs, mTOR bears a catalytic domain with significant homology to the lipid kinase phosphatidylinositol 3-kinase (PI3K); however, in spite of the sequence homology to lipid kinases, mTORs function exclusively as protein serine-threonine kinases.

The clinically active rapalogues inhibit mTOR kinase through the immunophilin FKBP-12 (FK506 binding protein-12), forming a FKBP12-rapamycin complex that binds to mTOR through the FRB domain [2]. The FRB domain is found only in the TOR proteins. The selectivity of these compounds for mTOR is remarkable: the drug directly attacks only one subpopulation of mTOR proteins residing in multiprotein complexes, termed mTORC1. Additional complexes, mTORC2, hold mTOR in a form that cannot be recognised or inhibited by FKBP12-rapamycin [3, 4]. 
Thereby, the rapamycin-FKBP12 complex can inhibit mTOR [5], preventing further phosphorylation of P70S6K, 4E-BP1 and, indirectly, other proteins involved in transcription and translation and cell cycle control. In addition to its immunosuppressive properties, sirolimus has been shown to exert anticancer effects through different mechanisms.

Sirolimus and its derivatives constitute a family of anti-neoplastic drugs that possess acceptable toxicity profiles.

The main toxicity observed with rapamycin (mTOR) inhibitors has been dose-dependent and consists primarily of hypercholesterolaemia, hypertriglyceridaemia and thrombocytopenia. Associated pulmonary toxicity in the form of diffuse interstitial pneumonia has been described with sirolimus and temsirolimus [6-11]. While extensive data have been published on sirolimusinduced lung toxicity, limited information about the pulmonary effects of temsirolimus exists in the literature $[12,13]$. No pathogenic mechanisms have been studied as potential causes of this visceral toxicity with temsirolimus.

Therefore, it is important to uncover the mechanistic role of factors that may induce pulmonary toxicity in sirolimus treatment. A cell-mediated autoimmune response has been suggested [8, 12], as well as a T-cell-mediated delayed type hypersensitivity mechanism [8, 10], through immunogenicity of sirolimus when it is binding to plasma proteins. Sirolimus becomes immunogenic, implicating $\mathrm{T}$-cell recognition of the processed antigen complex, release of cytokines, and recruitment and activation of macrophages and other inflammatory cells.

Usually, in the immunocompetent host, interstitial lung disease can be recognised as a heterogeneous group, as a syndrome with the following common clinical features: exertional dyspnoea; bilateral diffuse infiltrates on chest radiographs; physiological abnormalities with a restrictive lung defect, decreased diffusing capacity (DLCO) and abnormal alveolar-arterial oxygen gradient $\left(\mathrm{PaO}_{2}-\mathrm{PaO}_{2}\right)$ at rest or with exertion; absence of pulmonary infection and neoplasm; and histopathology with varying degrees of fibrosis and inflammation, with or without evidence of granulomatous or secondary vascular changes in the pulmonary parenchyma.

Temsirolimus-induced lung toxicity was first communicated after a randomised phase II study [6]. Out of 111 patients, $6 \%$ were reported to have possible non-specific pneumonitis. Additional evidence of possible temsirolimus-associated lung toxicity has been reported in 3 phase II studies [14-16].

The rare occurrences of sirolimus-associated pulmonary toxicity are in the form of diffuse interstitial pneumonitis. In contrast, patients that develop pulmonary abnormalities are more frequent, and these abnormalities were categorised into two different radiological patterns: ground glass opacities (with or without diffuse interstitial disease) and lung parenchymal consolidation [7].

Bronchoalveolar fluid analysis and lung biopsy, in selected case reports, revealed several distinct histologic features, including lymphocytic alveolitis, lymphocytic interstitial pneumonitis, bronchoalveolar obliterans organising pneumonia, focal fibrosis, pulmonary alveolar haemorrhage or a combination of these [10].

\section{Causes of interstitial lung disease}

Among different aetiologies, several drugs are well known to cause interstitial pulmonary disease. These include chemotherapeutic and cytotoxic agents [17-22]: methotrexate, bleomycin, mitomycin, nitrosureas, azathioprine, nitrogen mustard, procarbazine, busulfan, cyclophosphamide, melphalan, chlorambucil, non-steroidal anti-inflammatory agents, antibiotics, narcotic analgesics, antiarrhythmics and tricyclic antidepressants.

The list continues to increase as new antineoplastic agents and regimens are constantly being incorporated in treatments for cancer patients (Table 1). These novel agents have new mechanisms of action such as tyrosine kinase inhibitors or old agents with new indications like thalidomide. 
Table 1. Pulmonary complications generated by different chemotherapeutic agents

\begin{tabular}{ll}
\hline $\begin{array}{l}\text { Chemotherapeutic } \\
\text { agents }\end{array}$ & Pulmonary complications \\
\hline & \\
Erlotinib & Acute pneumonitis, ARDS \\
Etoposide & Acute pneumonitis, diffuse alveolar damage \\
Everolimus & Acute pneumonitis \\
Gefitinib & Acute pneumonitis, diffuse alveolar damage, diffuse alveolar haemorrhage, pulmonary fibrosis \\
Gemcitabine & Capillary lead syndrome/pulmonary oedema, ARDS, diffuse alveolar damage and haemorrhage, \\
& bronchospasm \\
Ifosfamide & Interstitial pneumonitis \\
Imatinib & Acute pneumonitis, pleural effusion, fluid retention and pulmonary oedema \\
Oxiplatin & Pulmonary fibrosis, respiratory failure, eosinophilic pneumonia \\
Taxanes & Acute pneumonitis, pleural effusion \\
Temozolamide & Acute pneumonitis \\
Temsirolimus & Acute pneumonitis \\
Thalidomide & Pulmonary embolism, organising pneumonia, acute pneumonitis, pleural effusion \\
Trastuzumab & Acute lung injury, acute pneumonitis, organising pneumonia, bronchospasm \\
\end{tabular}

\section{Histological features}

Interstitial lung disease is sometimes also known as interstitial pulmonary fibrosis. The terms interstitial lung disease, pulmonary fibrosis and interstitial pulmonary fibrosis are often used to describe the same condition.

Lung fibrosis is the common endpoint of a heterogeneous group of pathological entities termed interstitial lung diseases, which are characterised by chronic inflammation and progressive fibrosis of the pulmonary interstitium.

Interstitial lung disease is a generic term that includes a variety of chronic lung disorders such as idiopathic lung fibrosis (IPF), desquamative interstitial pneumonia (DIP), respiratory bronchiolitis interstitial lung disease (RB), lymphoid interstitial pneumonia (LIP), cryptogenic organising pneumonia (COP), diffuse alveolar damage (DAD) or acute interstitial pneumonia (AIP), and non-specific interstitial pneumonia (NSIP). The lung is affected in three ways: first, the lung tissue is damaged in some known or unknown way; second, the walls of the air sacs in the lung became inflamed; finally, scarring or fibrosis begins in the interstitium (or tissue between the air sacs) and the lung becomes stiff.

The term interstitium refers to the microscopic anatomic space bounded by the basement membranes of epithelial and endothelial cells. Within this interstitial space, fibroblast-like cells (mesenchymal and connective tissue cells) and extracellular matrix components (interstitial collagens, elastin, proteoglycans) are present. It is clear that the disease in not restricted to the interstitium, as it involves epithelial, endothelial and mesenchymal cells, macrophages and recruited inflammatory cells, secreted proteins and an aberration of matrix components within the alveolar walls. In addition, the disease process can be extended into the alveolar space, acini, bronchiolar lumen and bronchioles.

The bronchoalveolar lavage shows neutrophilic alveolitis. Alveolitis is the initial abnormality in the development of interstitial fibrosis: the accumulation of macrophages, neutrophils and lymphocytes within the lower respiratory tract damages alveolar structures.

The pathologic features of acute interstitial pneumonia include interstitial and intra-alveolar oedema, hyaline membrane formation and interstitial inflammation. Initially, the inrterstitium is expanded by oedema and inflammatory cells; this change is followed by loss of both type I pneumocyte epithelial cells and capillary endothelial cells. After the onset of the illness fibrosis becomes prominent, and hyperplastic type II pneumocyte cells line residual air spaces and the endstage honeycomb lung are found. The type II pneumocyte cells proliferate to resurface the denuded epithelial basal lamina and they cover the collapsed portions, rather than relining an intact and expanded alveolus [23]. 
The fibrosis is considered to result mainly in the proliferation of fibroblasts within the interstitium, along with an imbalance in collagen synthesis and breakdown. Fibrosis develops when alveolar injury is sufficiently severe that repair by epithelial cells is impossible and is thought to result mainly from the accumulation of fibroblasts and collagen within the interstitium $[24,25]$.

Cytotoxic-induced lung injury begins with an explosive inflammatory response in the alveolar wall. In the after-math of tissue destruction, a fi bro-proliferative response ensues, leading to extensive intra-alveolar granulation tissue comprised mainly of fibroblasts and their connective tissue products. As inflammation resolves, a fibro-proliferative process dominates in which fibroblasts move through the damaged epithelium and begin to lay down connective tissue products that results in dense intra-alveolar granulation tissue and impaired gas exchange. In these cases thickening of alveolar septa results from combinations of spindle cells, lymphocytes and plasma cells within an oedematous stroma. Type II pneumocytes often exhibiting considerable cytologic abnormality, lining the residual air spaces, and hyaline membranes, lining the alveolar septa, are present. Also small clusters of eosinophilic material, likely representing remnants of hyaline membranes, are found within the interstitium. Obliteration of lung architecture by fibroblast proliferation is observed and it becomes difficult to distinguish air spaces from interstitium.

\section{Pathogenesis}

The pathogenesis of lung fibrosis is complex and is thought to involve a number of processes that lead to an altered alveolar environment and to an abnormal repair process with accumulated fibrosis [23, 26, 27] (Table 2, Fig. 2).

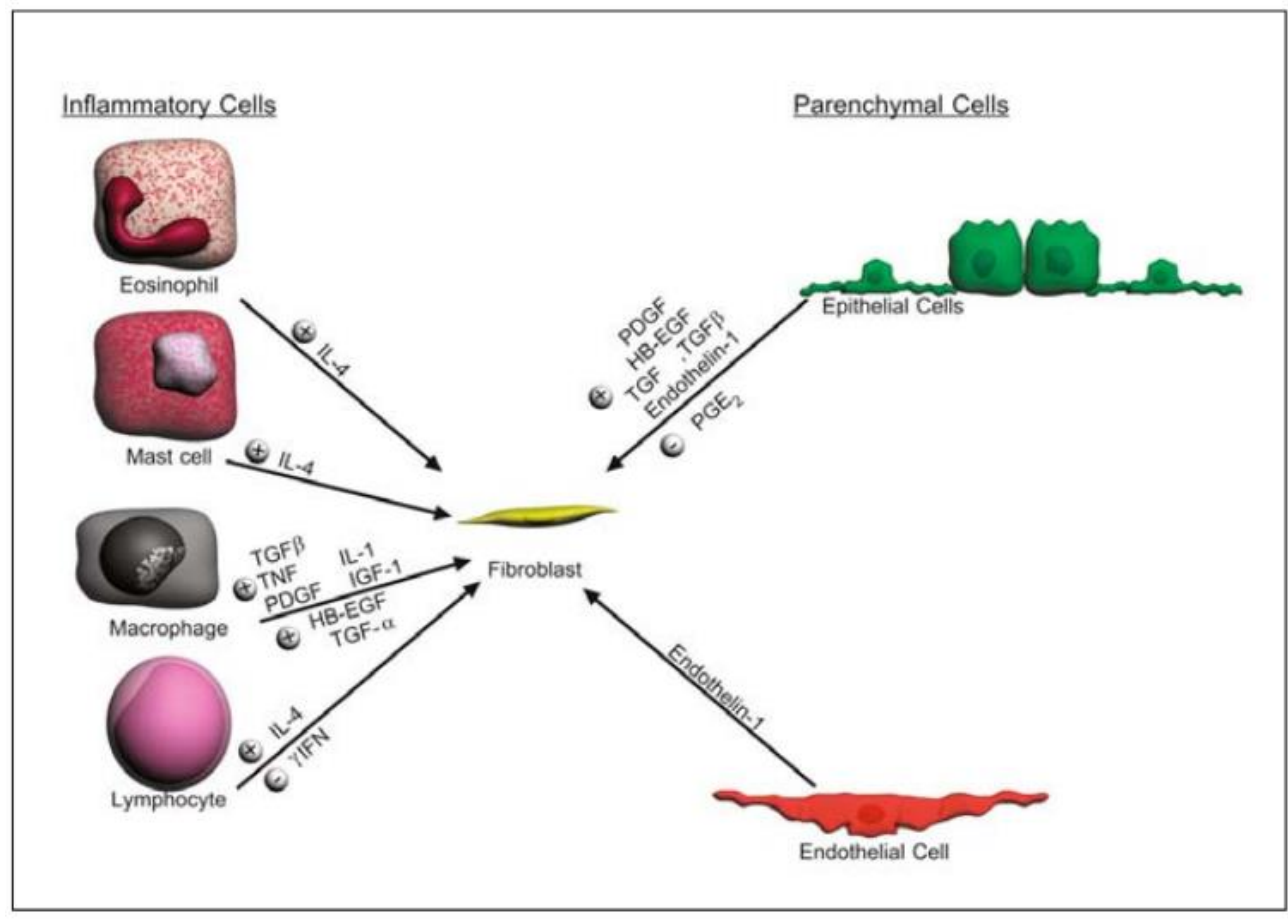

Fig. 2. Pathogenesis of pulmonary fibrosis involving the interaction of inflammatory cascade mediators (cytokine and growth factors) with parenchymal lung cells (epithelial and endothelial cells). Signals coming from inflammatory cells include stimulatory signals such as IL-4 (interleukin 4), IL-1 (interleukin 1), TGF- $\beta$ and $-\alpha$ (tumor growth factor beta and alpha), TNF (tumor necrosis factor), PDGF (plateled-derived growth factor), IGF-1 (insulin-like growth factor 1), and HBEGF (Heparin-binding EGF-like growth factor), and inhibitory signals such as IFN- $\gamma$ (interferon-gamma). Signals from epithelial cells include positive signals such as PDGF, HB-EGF, TGF, and endothelin-1, and inhibitory signals such as $\mathrm{PGE}_{2}$ (prostaglandin E2). From endothelial cells, it is sent the signal of endothelin 1 
Partial or complete collapse of alveoli and permanent apposition of their walls Influence with normal re-epithelisation

Incorporation of intra-alveolar exudates into the alveolar walls

Increased apposition of fibroblast, macrophages, lymphocytes and plasma cells in the interstitium

Greater deposition numbers of collagen and elastic fibres than normal

A large part of research in the area has focused on the pathogenesis of interstitial pulmonary disease. Characteristic features include fibrotic lesions with inflammatory cell infiltrates.

Inflammation can originate from processes of acute/chronic injury or irritation. The inflammatory response leads to lung infiltration by neutrophils (myeloperoxidase activity in the bronchoalveolar lavage total and differential count) and recruitment of mast cells and leukocytes to the site of the damage with a subsequent release of free radicals, including reactive oxygen species (ROS), lung myeloperoxidases, transforming growth factor (TGF)- $\beta$, inducible nitric oxide synthase (iNOS), nitrotyrosine and poly (ADP-ribose) polymerase (PARP). These free radicals are known to damage macromolecules, including lipids and DNA [28, 29]. In addition to the cellular and genomic damage that occurs as part of free-radical activity and other by-products, the increase of eicosanoid 5-lipoxygenase (5-LO) and decrease of prostaglandin $\mathrm{E}_{2}$ (PGE2) enhance fibroblast proliferation. The rate and magnitude of these processes are regulated by profibrotic cytokine diffusible factors such as platelet-derived growth factor (PDGF), IGF-1 and TGF- $\beta$, and by alveolar type II epithelial cell migration and proliferation, which cover the repaired basement membrane, closing the lung fibrosis process.

Interstitial pulmonary fibrosis results from three super-imposed processes of immune inflammation, tissue injury and attempted repair/fibrosis (Fig. 3).

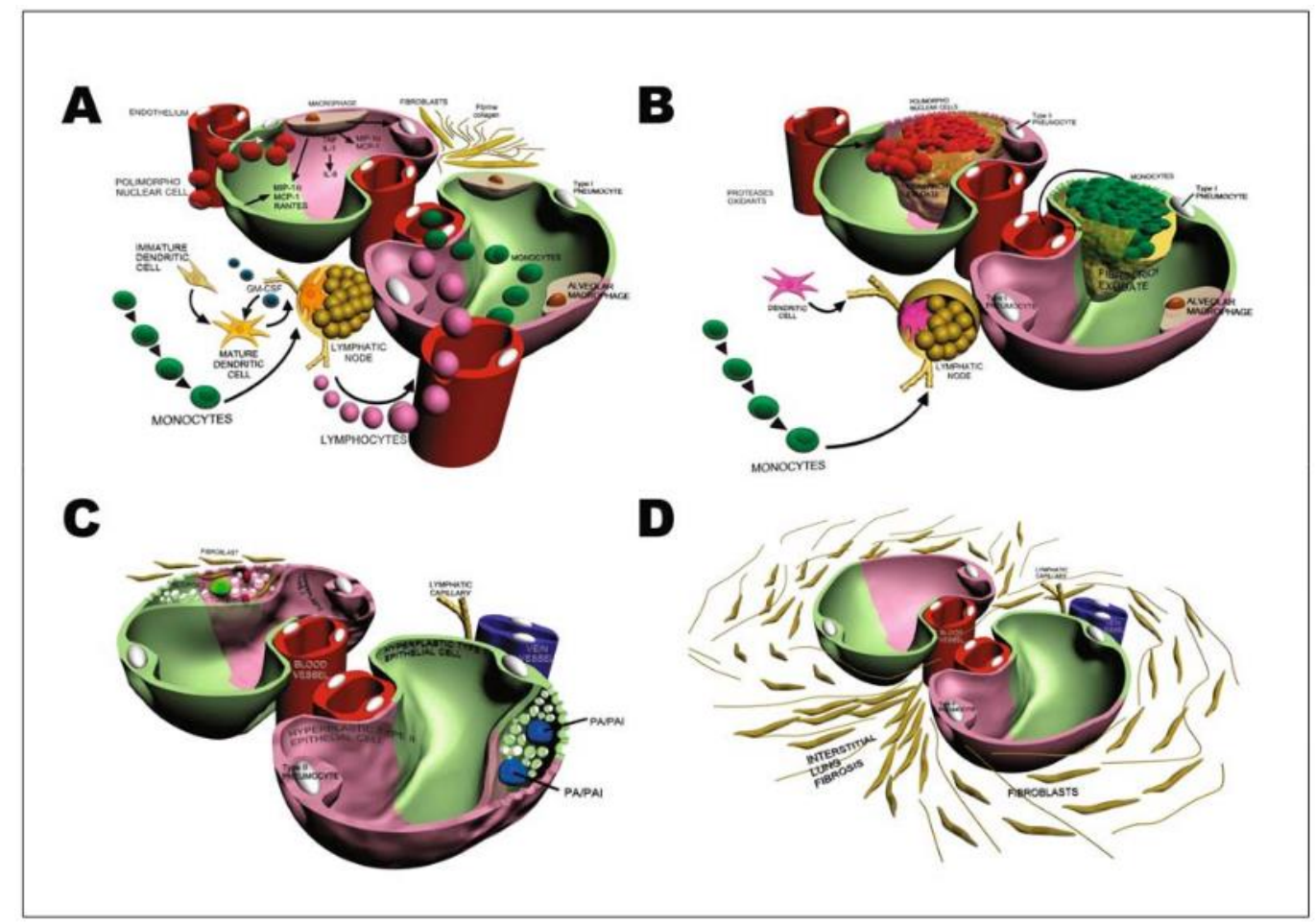

Fig. 3. Pathogenesis of idiopathic lung fibrosis results from the superimposed processes of immune inflammation, tissue injury, and attempted repair. A. Immune response. B. Epithelial cell injury. C. Repair of the damaged alveoli. D. Reepithelialization 
The aetiologic agent is presumed to interact with resident pulmonary immune cells ( $\mathrm{T}$ lymphocytes) to generate immune and inflammatory responses. The specific immune responses are initiated following migration of antigen-presenting cells and antigen-specific immune responses are likely to be generated early in the course of lung injury.

T-lymphocytes may play a dual role by contributing to both lung injury and the modulation of disease progression. he generation of specific immune response within the pulmonary interstitium is important in inducing the recruitment of inflammatory cells (i.e., monocytes, lymphocytes, polymorphonuclears, fibroblast, alveolar macrophages and dendritic cells).

Injury

Epithelial (type I and type II epithelium) cell injury is a hallmark of lung fibrosis; the alveolar basal lamina may also be destroyed. Recruited inflammatory cells cause epithelial cell injury, epithelial cell loss and basal lamina destruction.

\section{Repair/fibrosis}

Damaged alveoli require replacement of injured alveolar cells and the restoration of damaged extracellular matrix through fibrotic growth factors (TGF- $\beta$, TNF- $\alpha$, PDGF, IGF-I), fibronectin, thrombin, fibrinopeptides and arachidonic acid metabolites converting the fibrin-rich exudate into scar. Alveolar repair is accomplished by hyperplastic type II epithelial cells that proliferate and resurface the repaired basement membrane.

\section{$N F \kappa B / I K K-\beta$ : a master regulator of inflammation}

The nuclear factor (NF)-kappaB family is composed of homodimers and heterodimers of

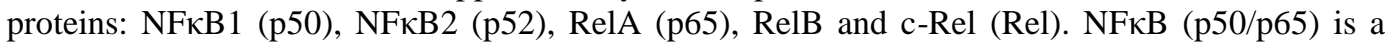
ubiquitous, constitutive and inducible heterodimer. The general NFKB traditionally refers to the p50/p65 (p50/RelA) heterodimer, which is an anti-apoptotic gene regulator; the p65 (RelA) subunit provides the gene regulatory function [30, 31].

NFKB (Fig. 4), a sequence-specific transcription factor, is a primary regulator of inflammatory responses [32]. $\mathrm{NF \kappa B}$ is a group of related homodimeric and heterodimeric transcription factors that are likely to activate distinct sets of target genes.

Their transcriptional actions play a central part in responses to inflammatory signalling not only through Toll-like receptors, but also through tumour necrosis factor (TNF) receptors and the IL-1 receptor, as well as in the diverse responses to other signals operating through the TNF receptor superfamily. They are also essential for responses to signalling through the variable antigen receptors of lymphocytes.

The classical pathway of $\mathrm{NF} \kappa \mathrm{B}$ activation operates through a heterodimer of p50 and p65. $\mathrm{NF \kappa B}$ dimers are held in the active state by a family of inhibitors called I $\mathrm{B}$. Receptor signalling leads to activation of a multisubunit I $\kappa \mathrm{B}$ kinase (IKK) complex, which phosphorylates I $\mathrm{KB}$.

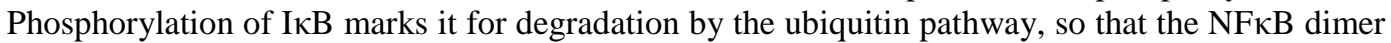
is liberated to translocate to the nucleus, bind DNA and active transcription. There are three main

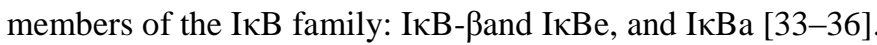

IкK- $\beta$ is required for its activation during acute inflammation [37] and for innate adaptative

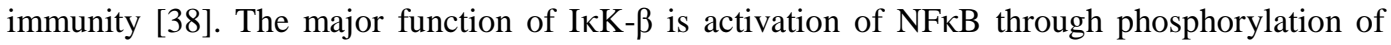
I $\kappa$ Bs $[38,39]$. After activation, NFKB mediates induction of proinflammatory cytokines, such as IL-1, IL-6 and TNF- $\alpha$ [37, 39]. As IL-1 and TNF- $\alpha$ activate myeloid cells to induce production of more proinflammatory cytokines, it is possible that myeloid cells may propagate an initial inflammatory signal. 


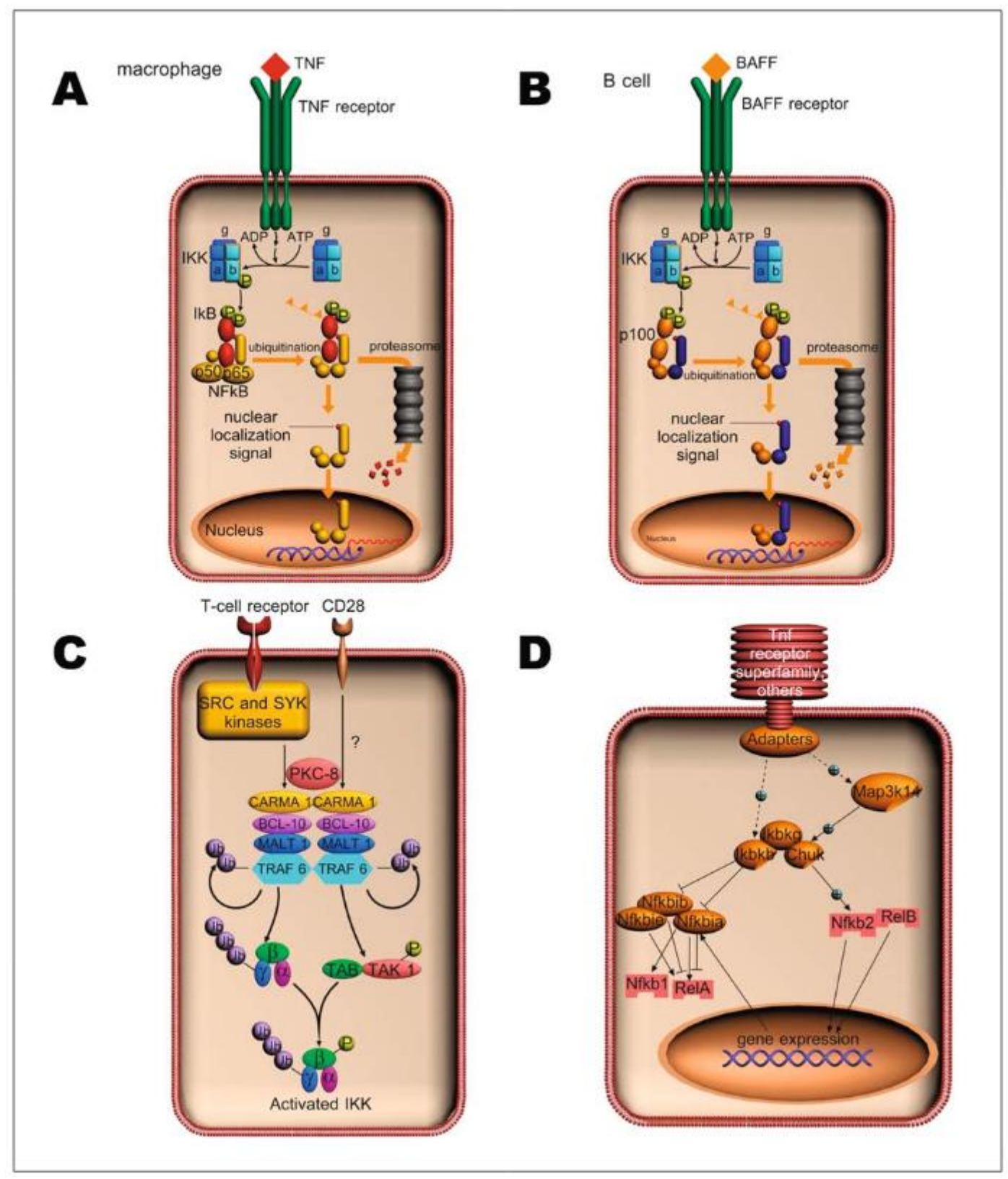

Fig. 4. NF-kB/lkk- $\beta$ pathway signalling. Nuclear factor $k B(N F-k B)$ is a primary regulator of inflammatory response; Ikk- $\beta$ is required for its activation during acute inflammation and for innate adaptive immunity

Macrophages and neutrophils are more important participants in systemic inflammatory responses [33], probably through IKK- $\beta$ delivery; notably, one of the many functions of macrophages is clearance of oxidised lipid deposits through scavenger receptors [40].

Although it is not clear (demonstrated) how temsirolimus causes activation of NFKB and its target genes in alveolar/interstitial cells, it is possible that excessive fatty acid oxidation in mitochondria generates peroxidation products [41] that may initiate a signalling cascade that culminates in NFKB activation.

This pathway suggests that $\mathrm{I} \kappa \mathrm{K}-\beta / \mathrm{NF} \mathrm{B}$ can be involved in the pathogenesis of interstitial pulmonary disease induced by rapamycin (mTOR) inhibitors. 
Recent developments in cell biology have led to the perception that ROS, including superoxide $\left(\mathrm{O}_{2}^{-}\right)$, nitric oxide (NO) and hydrogen peroxide $\left(\mathrm{H}_{2} \mathrm{O}_{2}\right)$, may be employed not only as cellular tools of destruction, but also to serve as mediators of cellular signal transduction (Fig. 5a). NO is synthesised from L-argine by the action of nitric oxide synthase (NOS) in a two-step oxidation process (Fig. 5b).

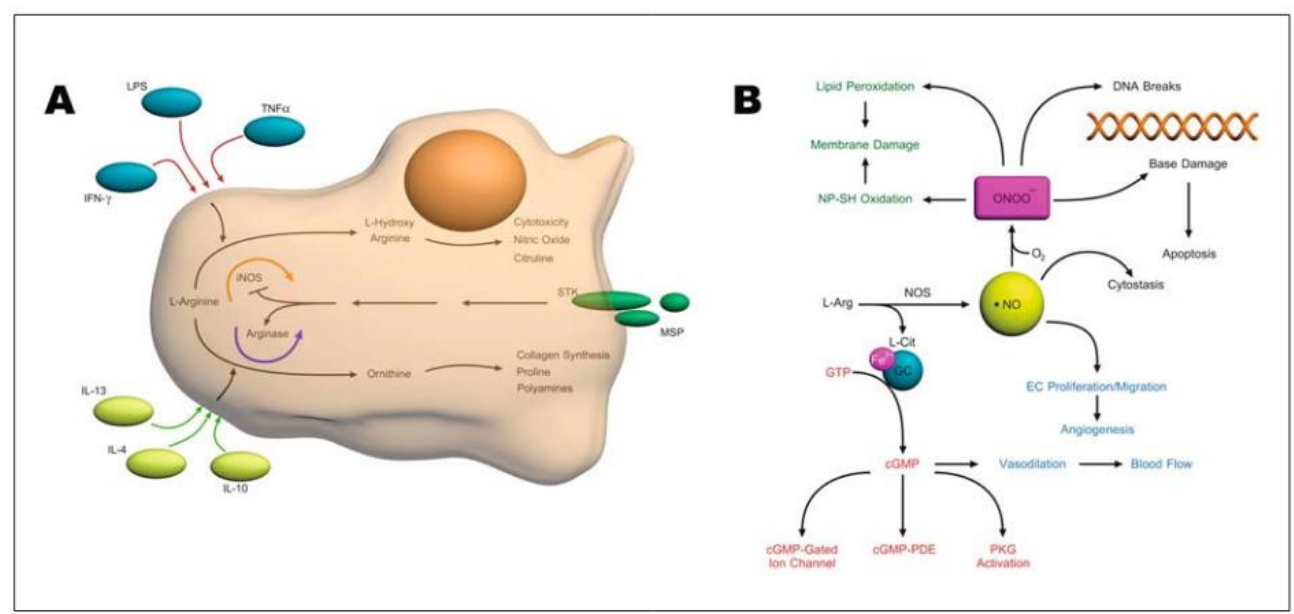

Fig. 5. Regulation of iNOS at the cellular levels. A. Cytokines controlling the iNOS induction in macrophages IFN- $\gamma$, produced mainly by NK cells, stimulates iNOS production. This IFN- $\gamma$-induced production of iNOS can be inhibited by IL. Upon stimulation of macrophages they produce TNF which synergizes with the IFN- $\gamma$-induced pathways and inhibits the inhibitory signals of IL. B. Reactive oxygen species (ROS) including superoxide $\left(\mathrm{O}_{2}^{-}\right)$, nitric oxide (NO) and hycrogen peroxide $\left(\mathrm{H}_{2} \mathrm{O}_{2}\right)$ may play as mediators of cellular signal transduction. Nitric oxide (NO) plays an important role in the regulation of a wide range of physiological processes (i.e. broncho-dilatation; vasodilatation and blood flow; proliferation; angiogenesis) and pathologic events (i.e. DNA damage; pulmonary fibrosis). Abbreviations: IL, interleukin; LPS, lipopolysaccharide; TNF, tumor necrosis factor; IFN, interferon; iNOS, inducible nitric oxide synthase; MSP, macrophage stimulating 1 (hepatocyte growth factor-like); Arg, arginine; GTP, guanosine triphosphate; cGMP, cyclic guanosine monophosphate; PKG, protein kinase G; PDE, phosphodiesterase; L-cit, L-citrulline; GC, guanylate cyclase; EC, endothelial cell, $\mathrm{ONOO}^{-}$, reactive oxygen compound

Previous studies on pulmonary fi brosis have mainly focused on the fibroproliferative process in the lung. There has been increasing interest in ROS generation in lung fi brosis [42, 43]. ROS, such as superoxide anions, hydrogen peroxides and hydroxyl radicals, have been demonstrated to be an important mediator in cytostatic-induced lung fi brosis [44, 45]. Excessive production of ROS is known to induce tissue damage or cell death, which could lead to several physiological and pathological processes.

ROS overproduction results in tissue injury, with activation of several intracellular signalling pathways leading to the production of pro-inflammatory cytokines [46]. DNA is a target for ROS activity as well. Radical oxygen species production, by determination of DNA damage, in turn activates PARP. This largely expressed nuclear protein contributes to the maintenance of genomic stability and to the repair of oxidative DNA damage [47]. Although PARP activity promotes cell survival, PARP activation depletes NAD+ and decreases ATP levels, thus leading to cell death after extensive DNA strand breaks [48]. Therefore, ROS produced in response to oxidative stress can contribute by multiple pathways to the pathogenesis of temsirolimus-induced lung injury.

Although the exact role of PARP in human lung fibrosis has not been investigated, it has been shown that PARP is implicated in experimental fibrosis and that PARP inhibition confers protection from inflammation and fibrosis in different animal models [49]. 
On the other hand, ROS can mediate tissue injury by an increased susceptibility to temsirolimus in patients lacking extracellular superoxide dismutase (SOD), which indicates that superoxide anion radicals play a main role in experimental fibrosis [50]. Superoxide reacts with nitric oxide to generate highly reactive metabolites such as peroxynitrite. This compound is able to oxidise proteins, resulting in direct nitration of tyrosine residues. Protein structure and function can be subsequently altered and enzymatic activity affected. Proteins containing nitrotyrosine residues have been detected in different pathologies associated with enhanced oxidative stress and increased levels of peroxynitrite [51, 52].

Oxidative stress is known to contribute to pulmonary fibrosis (Fig. 6), which occurs in two distinct phases. First, there is an acute phase characterised by an influx of inflammatory cells (macrophages and polymorphonuclear leukocytes). Secondly, this is followed by a chronic stage characterised by extracellular matrix remodelling and collagen deposition [53, 54]. An important feature of this model is that activated phagocytes release large amounts of ROS. The ROS generated include the superoxide anion, hydroxyl radicals, nitric oxide and hydrogen peroxide [55-57].

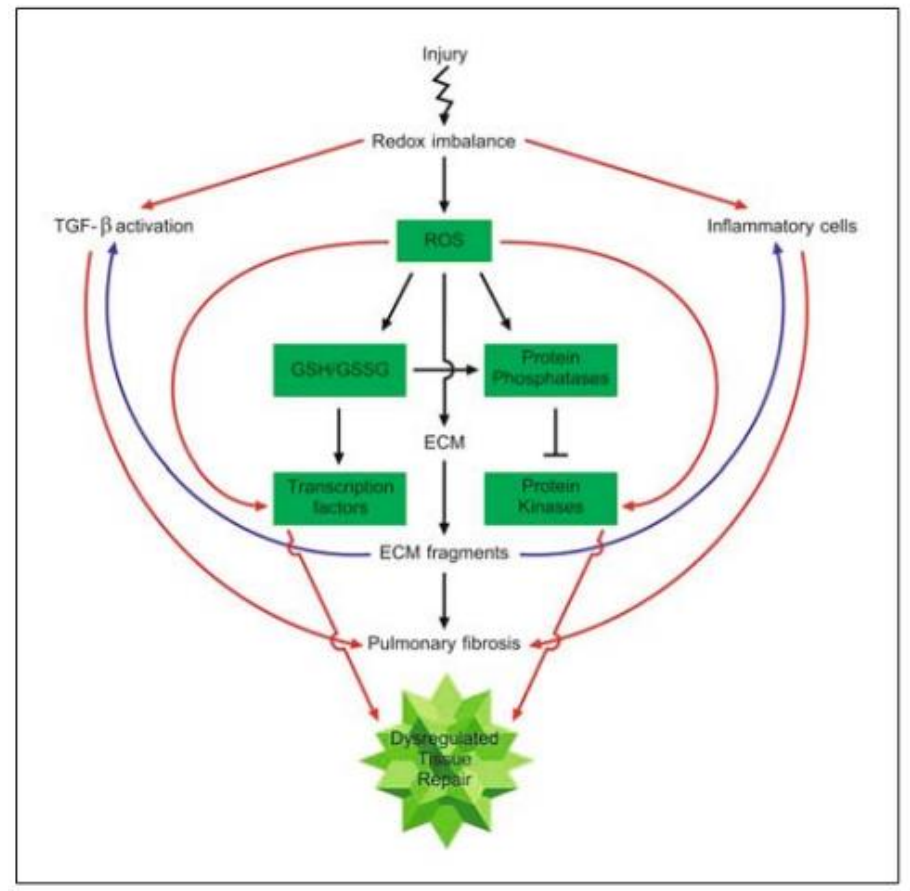

Fig. 6. Roles of reactive oxygen species (ROS) in the pathogenesis of pulmonary fibrosis. Some factors create a redox imbalance, causing a production of ROS. ROS degrade some components of the extracellular matrix (ECM), leading to ECM remodelling. The ECM fragments generated can cause inflammatory cell recruitment to the site and increase ROS production. Continuous inflammation leads to the fibrogenic process. ROS and ROS-induced ECM fragmentation products activate fibrotic cytokines/growth factors (i.e. TGF- $\beta$ ), thus favouring this process. EC-SOD can descend the oxidative stress in the lung parenchyma in human lung

NO, a highly reactive, diffusible and unstable radical, plays an important role in the regulation of a wide range of physiological processes. NO mediates vaso- and broncho- dilatation, which are involved in the physiological regulation of airway function [58].

NO is endogenously produced by NOS, a family of enzymes that currently include three different isoenzymes in mammals [51]: a soluble constitutively expressed enzyme found in high concentrations in the brain (bNOS, nNOS or NOS-1), a constitutively expressed endothelial membrane bound enzyme (eNOS, NOS-3) and an inducible enzyme (iNOS or NOS-2) that is associated with the cytotoxic function of macrophages. These three isoforms exhibit similarities in 
their structure and mechanisms of action. Calmodulin is required for the activity of all three isoforms.

iNOS is an inducible enzyme now known to be expressed in a wide variety of cell types. This isoenzyme may be distinguished from endothelial (eNOS) and neuronal NOS (nNOS), the other family members, by at least two criteria: fi rst, iNOS is not constitutively expressed in cells and regulation of this isoenzyme, in contrast to eNOS or nNOS, is widely considered to occur at the transcriptional level only; second, only iNOS produces micromolar NO concentrations, amounts that are high by comparison with the picomolar to nanomolar concentrations resulting from $\mathrm{Ca}^{2+}$ controlled NO production by the eNOS or nNOS [59]. Due to this property, iNOS expression and activity have also been linked to a number of human pathologies and particularly inflammation.

iNOS generates much larger quantities of nitric oxide than the constitutive isoforms and it is directly involved in host defence and in various models of inflammation [60, 61].

Exogenous nitric oxide is able to stimulate in vitro fibroblast proliferation [62] whereas iNOS up-regulation in lung fi broblasts is associated with the early proliferative response to cytokine stimulation [63].

Similarly, iNOS, which is the main source of NO during inflammation, and nitrotyrosine, a byproduct of peroxynitrite activity, are up-regulated in pulmonary fibrosis [64].

\section{Fibrogenic cytokines}

A number of cytokines have been shown to stimulate fibrotic events and include TGF- $\beta$, TNF$\alpha$, PDGF, granulocyte-macrophage colony-stimulating factor (GM-CSF), endothelin and interleukins (IL-1 $\beta$, IL-10, IL-13) [65].

TGF- $\beta$ is a multifunctional mediator capable of regulating cell proliferation and differentiation as well as synthesis of many components of the extracellular matrix [66-72]. Virtually all human cell types are able to produce TGF- $\beta$ which and they have a number of effects (Table 3 ) on cellular responses including modulating cell growth, migration, differentiation and apoptosis.

Table 3. TGF- $\beta$ and oxidative stress/cellular effects

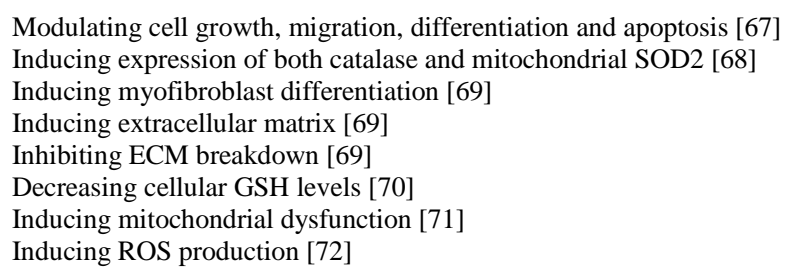

TGF- $\beta 1$ plays a central role in fibrotic disorders in different organs, including fibrosis of the lung (Fig. 7). In fact, it stimulates collagen and fibronectin production in fibroblasts [67]. TGF- $\beta$ was discovered as a factor that induces anchorage-independent growth of fibroblasts [68, 69], and thus, initially, it was thought to stimulate cell proliferation. On the other hand, it can suppress the production of proteases that degrade the extracellular matrix [66]. Morphogenic responses to TGF$\beta$ include cell migration and epithelial/endothelial-mesenchymal transition (EMTs), which are crucial during embryogenesis, and fibrotic diseases $[70,71]$. TGF- $\beta$ is a strong promoter of the epithelial-to-mesenchymal transition (EMT) in cooperation with the RAS-MAPK pathway [73]; also, in certain cases, TGF- $\beta$ induces EMT through the up-regulation of Snail, a transcriptional repressor of E-cadherin [74]. 


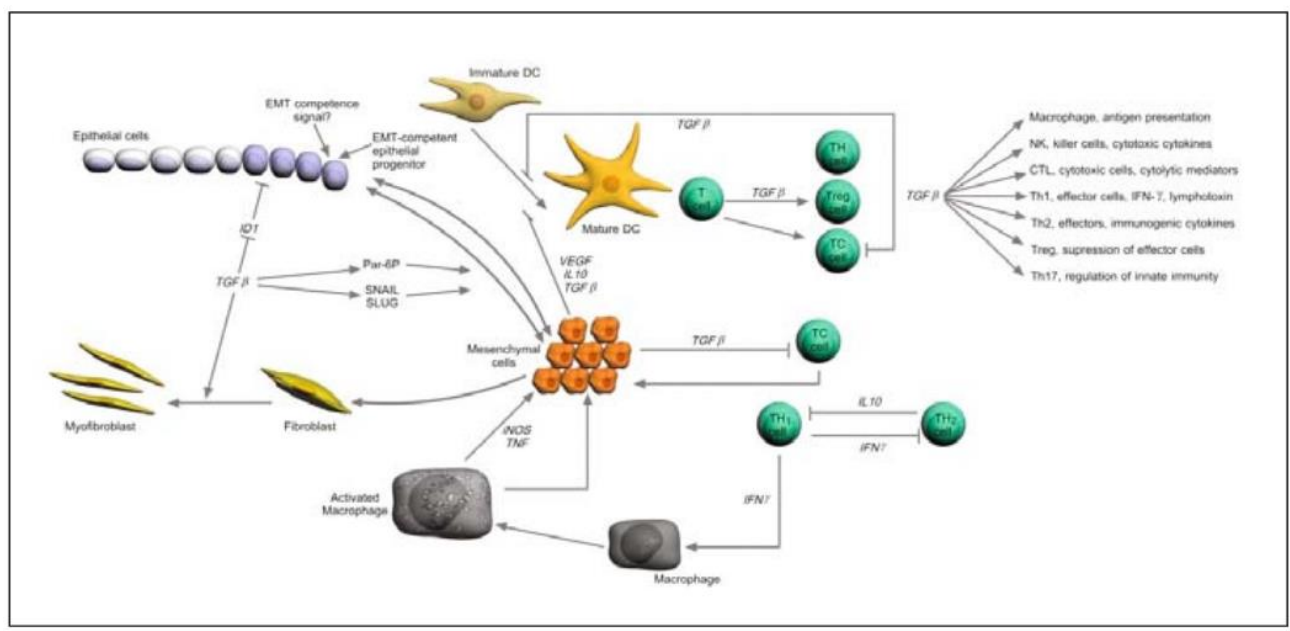

Fig. 7. TGF- $\beta$ is a pivotal protein in the inflammation and lung fibrosis dependent on the interaction of the alveolar macrophages activation, mesenchymal and dendritic cells (DC) and T-lymphocytes

The EMT is a characteristic change in polarised epithelial cells in which the cell-cell and cellmatrix adhesion is disrupted, the surrounding matrix is degraded and the cell phenotype is changed by rearranging its actin cytoskeleton to become more motile and invasive.

TGF- $\beta_{1}$ has been shown to be increased in bleomycininduced lung fibrosis in the alveolar inflammatory infiltrate [75]. The increase of TGF- $\beta 1$ mRNA precedes the biosynthesis of type I and type II procollagen in lung fibrosis [75].

The source of TGF- $\beta$ protein may be a result of increased gene expression by eosinophils and macrophages (Fig. 7) (active TGF- $\beta_{1}$ by alveolar macrophages is augmented after toxic drug administration) whereas later TGF- $\beta_{1}$ secretion remains elevated due to lung mesenchymal cells (myofibroblast and/or fibroblast-like cells, which are characterised by a high expression of $\alpha$ smooth muscle actin and collagen $[76,77]$.

TGF- $\beta$ is a key suppressor of destructive immune and inflammatory reactions $[78,79]$, and impaired immune regulation with excessive expansion of $\mathrm{T}$-cell populations. As an immunosuppressive cytokine, TGF- $\beta$ inhibits the development, proliferation and function of both the innate and the adaptative arcus of the immune system. Targets of TGF- $\beta$ include CD4+ effector T-cells (Th1 and Th2), CD8+ cytotoxic T-cells (CTLs), dendritic cells, NK cells and macrophages (Fig. 7). Additionally, TGF- $\beta$ stimulates the generation of regulatory T-cells (Treg), which inhibit effector T-cell function, and IL17-producing Th17-cells, which regulate NK and macrophages. By curtailing the activities of macrophages, natural killer cells and effector T-cells, TGF- $\beta$ suppresses inflammation to promote immune tolerance.

Tolerance can be particularly important in the airway mucosa, where reactions to opportunistic flora and polluting antigens must be restrained. Malfunctions in TGF- $\beta$ signalling are suspected to be a root cause of these conditions.

It is probable that the extent of inflammation and fibrosis in this model depends on the amount of active TGF- $\beta$ available [80]. Thus, TGF- $\beta$ may be associated with alterations in the phenotype of resident fibroblast found in human idiopathic pulmonary fibrosis [81]. 


\section{Conclusions}

One critical issue in the development of new cancer therapeutic agents is elucidating their biomarker, but an issue that could limit application of any drug is toxicity, so risk/benefit ratios must continually be assessed for patients receiving chemotherapy.

For example, rapamycin and its analogues cause specific antagonistic action on the function of the PI3 kinase-Akt-mTOR signalling pathway, induce G1-S cell cycle delay and apoptosis, and inhibit not only lymphocyte proliferation but also growth factor-induced smooth-muscle cell activation, which can explain their immunosuppressive properties and probably their lung side effects, too. This interstitial pneumonitis is a severe and infrequent side effect of sirolimus therapy. But even then, it is probable that a higher incidence of lung injury than that previously reported occurs when we use these drugs in poor-risk renal cancer and in other solid tumours, so the physicians must remain vigilant regarding its potential pulmonary complications, clinical features and management.

Nevertheless, the most important way to avoid this specific toxicity is try to discover those pathogenic mechanisms, biomolecular pathways, and signals of which is known or is thought that are crucial in the development of lung injury. The characterisation of mechanisms involved in the pathogenesis requires deeper investigation about rapamycin analogs, their target genes, and complex pathways activated in the alveolar and interstitial environment of damaged lung. Multiple cytokines and growth factors are able to modulate this lung injury and positive regulators would include the NFKB family, ROS and fibrogenic cytokines (TGF, TNF, GM-CSF, PDGF, endothelin and interleukins). Other proposed mechanisms include the recruitment of inflammatory cells, and changes in vascularity and the extracellular matrix.

Nowadays, management should start with the identification of factors that favour its appearance and of the fist and most common symptoms, dyspnoea and dry cough. After that, for diagnostic confirmation we need to be sure that there are not other causes of lung damage like infection, metastases and cardiac fault, which explain the symptoms and imaging results. The bronchoalveolar lavage can help us because no biological tests or markers have been validated.

Additionally, if we successfully make a precocious diagnosis of lung injury, the best treatment is the discontinuation of the rapamycin analogue because no drugs have demonstrated stoppage of the development of the damage beneficial enough for patients. In the absence of effective alternative therapies, pharmacological treatment of this toxicity is based on antioxidants, corticoids, carnosine, superoxide dismutase and amifostine. These drugs exert an antiinflammatory effect, attenuate the oxidative stress, and stop the redox imbalance to reduce the progressive lung damage. However, these are not real therapeutic advances so other pathways and novel therapeutic strategies may be found to block the molecular mechanism of fibrogenesis, to play major roles in stopping the progression of lung disease and, most of all, to improve the clinical management of patients.

To our knowledge, the present review is the first published of sirolimus-associated pneumonitis, providing new information about the disease development and the pathways implied. Encouragingly, this could be the way to investigate new treatments to resolve or to prevent this lung injury.

To summarise, this entity is likely to increase with wider use of rapamycin analogues in the treatment of solid tumours, so our knowledge of its pathogenesis, biomolecular pathways, and how to avoid and treat it is important.

\section{Acknowledgements}

GAG and VMV are supported by A Coruña University Hospital Foundation. MBC is hired through a research support programme from Instituto de Salud Carlos III (Spanish Government). 


\section{Conflict of interest}

The authors report no conflicts of interest. The authors alone are responsible for the content and writing of the paper.

\section{References}

1. Abraham RT (2004) PI3-kinase related kinases: "big" players in stress-induced signalling pathways. DNA Repair (Amst) 3:883-887

2. Chen J, Zheng XF, Brown EJ, Schreiber SL (1995) Identification of an 11-kDa FKBP12-rapamycin-binding domain within the 289-kDa FKBP12-rapamycinassociated protein and characterization of a critical serine residue. Proc Natl Acad Sci USA 92:4947-4951

3. Jacinto E, Loewith R, Schmidt A et al (2004) Mammalian TOR complex 2 controls the actin cytoskeleton and is rapamycin insensitive. Nat Cell Biol 6:1122-1128

4. Sarbassov DD, Ali SM, Kim DH et al (2004) Rictor, a novel binding partner of mTOR, defines a rapamycin-insensitive and raptor-independent pathway that regulates the cytoskeleton. Curr Biol 14:1296-1302

5. Chan S (2004) Targeting the mammalian target of rapamycin (mTOR): a new approach to treating cancer. Br J Cancer 91:1420-1424

6. Atkins MB, Hidalgo M, Stadler WM et al (2004) Randomized phase II study of multiple dose levels of CCI-779, a novel mammalian target of rapamycin kinase inhibitor, in patients with advanced refractory renal cell carcinoma. J Clin Oncol 22:909-918

7. Duran I, Siu LL, Oza AM et al (2006) Characterisation of the lung toxicity of the cell cycle inhibitor temsirolimus. Eur J Cancer 42:1875-1880

8. Morelon E, Stern M, Kreis H (2000) Interstitial pneumonitis associated with sirolimus therapy in renal-transplant recipients. N Engl J Med 343:225-226

9. Morelon E, Manzer-Bruneel MF, Peraldi MN, Kreis H (2001) Sirolimus; a new promising immunosuppressive drug. Towards a rationale for its use in renal transplantation. Nephrol Dial Transplant 16:18-20

10. Pham PT, Pham PC, Danovitch GM et al (2004) Sirolimus-associated pulmonary toxicity. Transplantation 77:1215-1220

11. Singer SJ, Tiernan R, Sullivan EJ (2000) Interstitial pneumonitis associated with sirolimus therapy in renal-transplant recipients. N Engl J Med 343:1815-1816

12. Mahalati K (2000) Bronchiolitis obliterans and organizing pneumonia in renal transplant recipients. Transplantation 69:1581

13. Vignot S, Faivre S, Aguirre D, Raymond E (2005) mTOR-targeted therapy of cancer with rapamycin derivatives. Ann Oncol 16:525-537

14. Chan S, Scheulen ME, Johnston S et al (2005) Phase II study of temsirolimus (CCI779 ), a novel inhibitor of mTOR, in heavily pretreated patients with locally advanced or metastatic breast cancer. J Clin Oncol 23:5314-5322

15. Galanis E, Buckner JC, Maurer MJ et al; North Central Cancer Treatment Group (2005) Phase II trial of emsirolimus (CCI-779) in recurrent glioblastoma multiforme: a North Central Cancer Treatment Group Study. J Clin Oncol 23:5294-5304

16. Witzig TE, Geyer SM, Ghobrial I et al (2005) Phase II trial of single-agent Temsirolimus (CCI-779) for relapse mantle cell lymphoma. J Clin Oncol 23:5347-5356

17. Israel-Biet D, Labrune S, Huchon GJ (1991) Drug-induced lung disease: review, 1990. Eur Respir J 4:465-478

18. Kilburn KH (1980) Pulmonary disease induced by drugs. In: Fishman AP (ed.) Pulmonary disease and disorders. McGraw-Hill, New York, pp 707-724

19. Rosenow EC, Myers JL, Swensen SJ, Pisani RJ (1992) Drug-induced pulmonary disease: an update. Chest 102:239-250

20. Vahid B, Marik PE (2008) Pulmonary complications of novel antineoplastic agents for solid tumors. Chest 133:528-538

21. Weis RB, Muggia FM (1980) Cytotoxic druginduced pulmonary disease: update. Am J Med 68:259-266

22. Whimster WF, de Poitiers W (1982) The lung. In: Riddell RH (ed.) Pathology of druginduced and toxic diseases. Churchill Livingstone, New York, pp 167-200

23. Katzebstein ALA (1985) Pathogenesis of "fibrosis" in interstitial pneumonia: an electron microscopic study. Hum Pathol 16:1015-1024

24. Crystal RG, Bitterman PB, Rennard SI et al (1984) Interstitial lung disease of unknown cause. Disorders characterized by chronic inflammation of the lower respiratory tract. $\mathrm{N}$ Engl J Med 310:154-166 
25. Rennard S, Bitterman P, Crystal R (1983) Response of the lower respiratory tract to injury. Mechanisms of repair of the parenchymal cells of the alveolar wall. Chest 84:735-739

26. Liebow A (1975) Definition and classification of interstitial pneumonia in human pathology. Prog Respir Res 8:1-33

27. Spencer H (1975) Pathogenesis of interstitial fibrosis of the lung. Prog Respir Res 8:3444

28. Hussain SP, Hofseth LJ, Haris CC (2003) Radical causes of cancer. Nat Rev Cancer 3:276-285

29. Ohshima H, Tatemichi M, Sawa T (2003) Chemical basis of inflammation-induced carcinogenesis. Arch Biochem Biophys 417:3-11

30. Chen LF, Williams SA, Mu Y et al (2005) NFkappaB RelA phosphorylation regulates RelA acetylation. Mol Cell Biol 25:7966-7975

31. Kiernan R (2003) Post-activation turn-off NFkappa B-dependent transcription is regulated by acetylation of p65. J Biol Chem 278:2758-2766

32. Barnes PJ, Karin M (1997) Nuclear factor-kappaB: a pivotal transcription factor in chronic inflammatory diseases. N Engl J Med 336:1066-1071

33. Ghosh S, Karin M (2002) Missing pieces in the NF-kB puzzle. Cell 109:S81-96

34. Hoffmann A, Levchenko A, Scott ML, Baltimore D (2002). The IkappaB-NF-kappaB signalling module: temporal control and selective gene activation. Science 298:12411245

35. Hoffmann A, Leung TH, Baltimore D (2003) Genetic analysis of NF-kappaB/rel transcription factors defines functional specificities. EMBO J 22:5530-5539

36. Jacobs MN, Harrison SD (1998) Structure of an I-kBa/NF-kB complex. Cell 95:749758

37. Chen LW, Egan L, Li ZW et al (2003) The two faces of IKK and NF-kappaB inhibition: prevention of systemic inflammation but increased local injury following intestinal ischemia-reperfusion. Nat Med 9:575-581

38. Li Q, Verma IM (2002) NF-kB regulation in the immune system. Nat Rev Immunol 2:725-734

39. Maeda S, Chang L, Li ZW et al (2003) IKKbeta is required for prevention of apoptosis mediated by cell-bound but not by circulating TNF alpha. Immunity 19:725-737

40. Moore KJ, Rosen ED, Fitzgerald ML et al (2001) The role of PPAR-gamma in macrophage differentiation and cholesterol uptake. Nat Med 7:41-47

41. Petersen KF, Dufour S, Befroy D et al (2004) Impaired mitochondrial activity in the insulinresistant offspring of patients with type 2 diabetes. N Engl J Med 350:664-671

42. Castranova VD, Porter L, Millecchia JY et al (2002) Effect of inhaled crystalline silica in rat model: time course of pulmonary reactions. Mol Cell Biochem 234-235:177-184

43. Shukla A, Ramos-Nino M, Mossman B (2003) Cell signalling and transcription factor activation by asbestos in lung injury and disease. Int J Biochem Cell Biol 35:1198-1209

44. Arslan SO, Zerin M, Vural H, Coskun A (2002) The effect of melatonin on bleomycininduced pulmonary fibrosis in rats. J Pineal Res 32:21-25

45. Chen J, Stubbe J (2004) Bleomycins: a new methods will allow reinvestigation of old issues. Curr Opin Cell Biol 8:175-181

46. Hubbard AK, Timblin CR, Shukla A et al (2002) Activation of NF-kB-dependent gene expression by silica in lungs of luciferase reporter mice. Am J Physiol Lung Cell Mol Physiol 282:L968-975

47. Benjamin RC, Gill DM (1980) Poly(ADP-ribose) synthesis in vitro programmed by damaged DNA. A comparison of DNA molecules containing different types of strands breaks. J Biol Chem 255:10502-10508

48. Cosi C, Marien M (1999) Implication of poly(ADP-ribose)polymerase (PARP) in neurodegeneration and brain energy metabolism. Decreases in mouse brain NAD+ and ATP caused by MPTP are prevented by the PARP inhibitor benzamide. Ann NY Acad Sci 890:227-239

49. Virag L (2005) Poly(ADP-ribosyl)ation in asthma and other lung diseases. Pharmacol Res 52:83-92

50. Fattman CL, Chang LY, Termin TA et al (2003) Enhanced bleomycin-induced pulmonary damage in mice lacking extracellular superoxide dismutase. Free Radic Biol Med 35:763-771

51. Griffith OW, Stuehr DJ (1995) Nitric oxide synthase: properties and catalytic mechanism. Annu Rev Physiol 57:707-736

52. Halliwell B (1997) What nitrates tyrosine? Is nitrotyrosine specific as a biomarker of peroxynitrite formation in vivo? FEBS Lett 411:157-160

53. Adamsson IY, Bowden DH (1974) The pathogenesis of bleomycin-induced pulmonary fibrosis in mice. Am J Pathol 77:185-197

54. Fasske E, Morgenroth K (1983) Experimental bleomycin lung in mice. A contribution to the pathogenesis of pulmonary fibrosis. Lung 161:133-146 
55. Chakrabarti S, Makrigiorgos GM, O’Brien K et al (1996) Measurement of hydroxyl radicals catalyzed in the immediate vicinity of DNA by metal-bleomycin complexes. Free Radic Biol Med 20:777-783

56. Conley NS, Yarbro JW, Ferrari HA, Zeidler RB (1986) Bleomycin increases superoxide anion generation by pig peripheral alveolar macrophages. Mol Pharmacol 30:48-52

57. Tarnell EW, Oliver BL, Johnsson GM et al (1992) Superoxide anion production by rat neutrophils at various stages of belomycin-induced lung injury. Lung 170:41-50

58. Moncada S, Palmer RM, Higgs EA (1989) Biosynthesis of nitric oxide from L-arginine. A pathway for the regulation of cell function and communication. Biochem Pharmacol 38:1709-1715

59. Forstermann U, Gath I, Schwarz P et al (1995) Isoforms of nitric oxide synthase. Properties, cellular distribution and expressional control. Biochem Pharmacol 50:13211332

60. Cuzzocrea S, Zingarelli B, Hake P et al (1998) Antiinflammatory effects of mercaptoethylguanidine, a combined inhibitor of nitric oxide synthase and peroxynitrite scavenger, in carrageenan-induced models of inflammation. Free Radic Biol Med 24:450-459

61. Wei XD, Charles IG, Smith A et al (1995) Altered immune responses in mice lacking inducible nitric oxide synthase. Nature 375:408-411

62. Gansauge S, Gansauge F, Nussler AK et al (1997) Exogenous, but not endogenous, nitric oxide increases proliferation rates in senescent human fibroblasts. FEBS Lett 410:160-164

63. Romanska HM, Polak JM, Colemena RA et al (2002) iNOS gene upregulation is associated with the early proliferative response of human lung fibroblasts to cytokine stimulation. J Pathol 197:372-379

64. Saleh D, Barnes PJ, Giaid A (1997) Increased production of the potent oxidant peroxynitrite in the lungs of patients with idiopathic pulmonary fibrosis. Am J Respir Crit Care Med 155:1763-1769

65. Ask K, Maretin GE, Kolb M, Gauldie J (2006) Targeting genes for treatment in idiopathic pulmonary fibrosis: challenges and opportunities, promises and pitfalls. Proc Am Thorac Soc 3:389-393

66. Sporn MB, Roberts AB, Wakefield LM, de Crombrugghe B (1987). Some recent advances in the chemistry and biology of transforming growth factor- $\beta$. J Cell Biol 105:1039-1045

67. Fine A, Goldstein RH (1987) The effect of transforming growth factor- $\beta$ on cell proliferation and collagen formation by lung fibroblasts. J Biol Chem 262:3897-3902

68. Moses HL, Branum EL, Proper JA, Robinson RA (1981) Transforming growth factor production by chemically transformed cells. Cancer Res 41:2842-2848

69. Roberts AB, Lamb LC, Newton DL et al (1980) Transforming growth factors: isolation of polypeptides from virally and chemical transformed cells by acid/ethanol extraction. Proc Natl Acad Sci USA 77:3494-3498

70. Gotzman J, Mikula M, Eger A et al (2004) Molecular aspects of epithelial cell plasticity: implications for local tumor invasion and metastasis. Mutat Res 566:9-20

71. Tosh D, Slack JM (2002) How cells changes their phenotype. Nat Rev Mol Cell Biol 3:187-194

72. Roberts AB, Sporn MB (1993) Physiological actions and clinical applications of transforming growth factor- $\beta$ (TFG- $\beta$ ). Growth Factors 8:1-9

73. Janda E, Lehmann K, Killisch I et al (2002) Ras and TGF(beta) cooperatively regulate epithelial cell plasticity and metastasis: dissection of Ras signalling pathways. J Cell Biol 156:299-313

74. Peinado H, Quintanilla M, Cano A (2003) Transforming growth factor beta-1 induces snail transcription factor in epithelial cell lines: mechanisms for epithelial mesenchymal transition. J Biol Chem 278:21113-21123

75. Hoyt DG, Lazo JS (1988) Alterations in pulmonary mRNA encoding procollagens, fibronectin and transforming growth factor- $\beta$ precede bleomycin-induced pulmonary fibrosis in mice. J Pharmacol Exp Ther 246:765-771

76. Barral-Neto M, Barral A, Brownel CE et al (1992) Transforming growth factor $\beta$ in leishmanial infection: a parasite escape mechanism. Science 257:545-548

77. Zhang K, Rekhter MD, Gordon D, Phan SH (1994) Localization of myofibroblasts in the lung, and their role in collagen gene expression in a model of pulmonary fibrosis. Am J Pathol 145:114-125

78. Li MO, Wan YY, Sanjabi S et al (2006) Transforming growth factor-beta regulation of immune responses. Annu Rev Immunol 24:99-146

79. Rubtsov YP, Rudensky AY (2007) TGFbeta signalling in control of T-cell-mediated self-reactivity. Nat Rev Immunol 7:443-453 
80. Khalil N, Corne S, Whitman C, Yacyshyn H (1996) Plasmin regulates the activation of cell-associated latent TGF- $\beta$ secreted by rat alveolar macrophages after in vivo bleomycin injury. Am J Resp Cell Mol Biol 15:252-259

81. Broekelmann TJ, Limper AH, Colby TV, McDonald JA (1991) Transforming growth factor $\beta 1$ is present at sites of extracellular matrix gene expression in human pulmonary fibrosis. Proc Natl Acad Sci USA 88:6642-664 